\title{
Attitudes and practice patterns for maintaining relative dose intensity of chemotherapy in outpatient clinics: results of a Japanese web-based survey
}

\author{
Hitomi Sakai, Noriyuki Katsumata ${ }^{*}$ and Genmu Kadokura
}

\begin{abstract}
Background: This analysis was undertaken to evaluate the practice patterns of Japanese physicians regarding curative-intent chemotherapy, especially in outpatient settings, and to define factors negatively affecting the maintenance of relative dose intensity (RDI).

Methods: We performed a web-based questionnaire survey of Japanese physicians involved in malignant lymphoma chemotherapy (Group ML) or in breast cancer chemotherapy (Group BC). The questionnaire inquired how they manage low-risk febrile neutropenia (FN) caused by initial chemotherapy for diffuse large B-cell lymphoma(DLBCL) or by adjuvant chemotherapy for breast cancer in an outpatient setting.

Results: Valid responses were obtained from 185 physicians in Group ML and 160 in Group BC. In Group ML, 76 \% ( $n=141)$ of the physicians were board-certified hematologists, while $82 \%(n=131)$ of the physicians in Group BC were board-certified surgeons. A significantly higher proportion of physicians in Group ML responded that "dose reduction is not required for the subsequent course of chemotherapy after the first episode of FN" than in Group $B C$ (ML versus $B C ; 77 \%$ versus $31 \% ; P<0.001$ ). Significantly higher proportions of physicians in Group ML were more likely to prophylactically administer antibiotics or granulocyte-colony stimulating factor (G-CSF; ML versus BC; antibiotics: $36 \%$ versus $26 \%, P=0.049 ;$ G-CSF: $25 \%$ versus $16 \%, P=0.047)$. Eighty six percent $(n=159)$ of Group $\mathrm{ML}$ and $70 \%(n=112)$ of Group BC responded that "emergency outpatient unit is open at all hours".

Conclusions: Japanese physicians are more likely to administer reduced doses of chemotherapy to patients with breast cancer than to patients with malignant lymphoma. Supportive infrastructures should be improved to ensure the provision of adequate chemotherapy to all cancer patients.
\end{abstract}

\section{Background}

Maintaining dose intensity is important for achieving the full benefits of chemotherapy in patients with potentially curable non-Hodgkin's lymphoma and breast cancer. In 1990, Epelbaum et al. reported a strong association between the relative dose intensity (RDI) of a standard CHOP (cyclophosphamide, doxorubicin, vincristine, prednisone) regimen and 5-year survival among 95 patients with diffuse large-cell lymphoma (DLCL) [1]. The 5-year

\footnotetext{
* Correspondence: nkatsuma@nms.ac.jp

All authors contributed equally to this work

Department of Medical Oncology, Nippon Medical School Musashikosugi

Hospital, 1-396, Kosugi-machi, Nakahara-ku, Kawasaki City, Kanagawa
} 211-0063, Japan survival rate was $80 \%$ in patients who received more than the median average RDI, whereas it was only $32 \%$ in those who received less than the median average RDI $(P<$ 0.001). Similarly, analysis of the RDIs of three doxorubicin-based regimens (including CHOP) in 115 patients with DLCL revealed that RDI of doxorubicin greater than $75 \%$ was the most important predictor of survival [2]. A recently published retrospective analysis by Bosly et al. showed that survival of patients with diffuse large Bcell lymphoma (DLBCL) improved with an increasing average RDI (ARDI) of CHOP-21. Median survival was 7.08 years in those who received $>90 \%$ of the ARDI, significantly longer than in those who received $\leq 90 \%$ of the ARDI $(P=0.002)$ [3]. In 1981, Bonadonna et al. reported a 
clear dose-response effect for CMF (cyclophosphamide, methotrexate, and 5-fluorouracil [5-FU]) chemotherapy in 449 women with breast cancer [4]. Their results showed that patients receiving $\geq 85 \%$ of the planned CMF dose had a 5-year relapse-free survival (RFS) rate of $77 \%$, compared with $48 \%$ in patients receiving $<65 \%$ of the planned dose. In 1995, 20-year follow-up data from the same group confirmed that RFS and overall survival (OS) were substantially better in patients who received $\geq 85 \%$ of their planned dose than in those who received lower doses [5].

In 1998, Budman et al. reported the results of a randomized trial of adjuvant CAF (cyclophosphamide, doxorubicin, 5-FU) for stage II breast cancer patients. In total, 1,550 breast cancer patients were randomly assigned to one of three treatment arms: high-, moderate-, or lowdose intensity treatments [6]. The results revealed that the patients who received high- or moderate-dose intensity had significantly longer disease-free survival $(P<$ $0.001)$ and $\mathrm{OS}(P=0.004)$ than those who received low-dose intensity.

Recently, some study protocols specify that patients who have an initial episode of febrile neutropenia (FN) should additionally receive granulocyte-colony stimulating factor (G-CSF) or prophylactic antibiotics in subsequent cycles, and dose modification of chemotherapy is unnecessary [7-9]. If there is a second FN episode despite G-CSF or antibiotic support, the protocols recommend a reduction in chemotherapy dose.

However, studies of patients with aggressive nonHodgkin's lymphoma and early-stage breast cancer in the United States have reported that nearly half of such patients receive reduced dose-intensity chemotherapy $[10,11]$. Additionally, how Japanese physicians manage outpatient chemotherapy and apply supportive measures to maintain RDI remains largely unknown. In Japan, chemotherapy for malignant lymphoma has been traditionally administered by hematologists, while chemotherapy for breast cancer is administered mainly by surgeons. This study was designed to clarify physicians' attitudes and practice patterns with respect to curativeintent chemotherapy and to define factors that negatively affect RDI maintenance in Japan.

\section{Methods}

We posted a questionnaire on a Japanese web site for physicians. Registration was required to access the questionnaire and those who completed the questionnaire could receive points from the web site as an incentive. The target respondents were physicians involved in the treatment of malignant lymphoma (Group ML) and those involved in the treatment of breast cancer (Group BC). Respondents in Group ML had to: 1) be a member of the Japanese Society of Hematology; 2) work at a hospital with more than 20 beds; 3 ) attend more than five patients with
Non-Hodgkin's lymphoma who receive chemotherapy; and 4) attend at least one patient who received R-CHOP (rituximab, cyclophosphamide, doxorubicin, vincristine, prednisone) in the past year. Respondents in Group BC had to: 1) be a member of the Japanese Breast Cancer Society; and 2) attend more than 15 patients who received neoadjuvant or adjuvant chemotherapy in the past year. The number of current members of the Japanese Society of Hematology is around 6,400, whereas number of current members of the Japanese Breast Cancer Society is around 9,800, $68 \%$ of which are surgeons.

In the questionnaire, we described a patient who received first-line chemotherapy for DLBCL in Group ML and a patient who received adjuvant chemotherapy for early breast cancer in Group BC. In the clinical scenarios, the patients suffer from low risk FN with The Multinational Association for Supportive Care in Cancer (MASCC) scores $\geq 21[12,13]$ and in Talcott group 4 [14]. The questionnaire inquired about the management of FN and subsequent cycles of chemotherapy. The questions asked in the survey are listed in Table 1 . This survey was administered in Japanese. The surveillance period was from November 30 through December 11, 2012.

All survey data were coded and analyzed with the use of standard EZR (Saitama Medical Center, Jichi Medical University), which is a graphical user interface for $\mathrm{R}$ (The $\mathrm{R}$ Foundation for Statistical Computing, version 2.13.0) [15]. More precisely, it is a modified version of $R$ commander (version 1.6-3) that includes statistical functions that are frequently used in biostatistics. For comparisons of categorical variables, Fisher's exact tests were used.

The execution of the survey followed the ethical principles outlined in the Declaration of Helsinki regarding human clinical research. The approval of the Ethics Committee of Nippon Medical School Musashikosugi Hospital was not required. This is because the regulation of the Ethics Committee of Nippon Medical School does not stipulate that a questionnaire survey for physicians requires ethical committee approval. Moreover, this is an anonymous questionnaire survey and we only use pseudonymized data.

\section{Results}

Table 2 lists the participant characteristics. Valid responses were obtained from 185 respondents in Group ML and 160 in Group BC; there were no invalid responses. In Group ML, $76 \%(n=141)$ of the respondents were boardcertified hematologists, and $10 \%(n=18)$ were boardcertified oncologists. In Group BC, $82 \%(n=131)$ were board-certified surgeons and $36 \%(n=58)$ were boardcertified breast surgeons. Overall, $11 \%(n=17)$ of the respondents in Group BC were board-certified oncologists. In Group ML, $32 \%(n=59)$ of the respondents were working at academic medical centers, $32 \%(n=59)$ at cancer centers or public hospitals, and $36 \%(n=67)$ at private 
Table 1 Questions asked in the survey

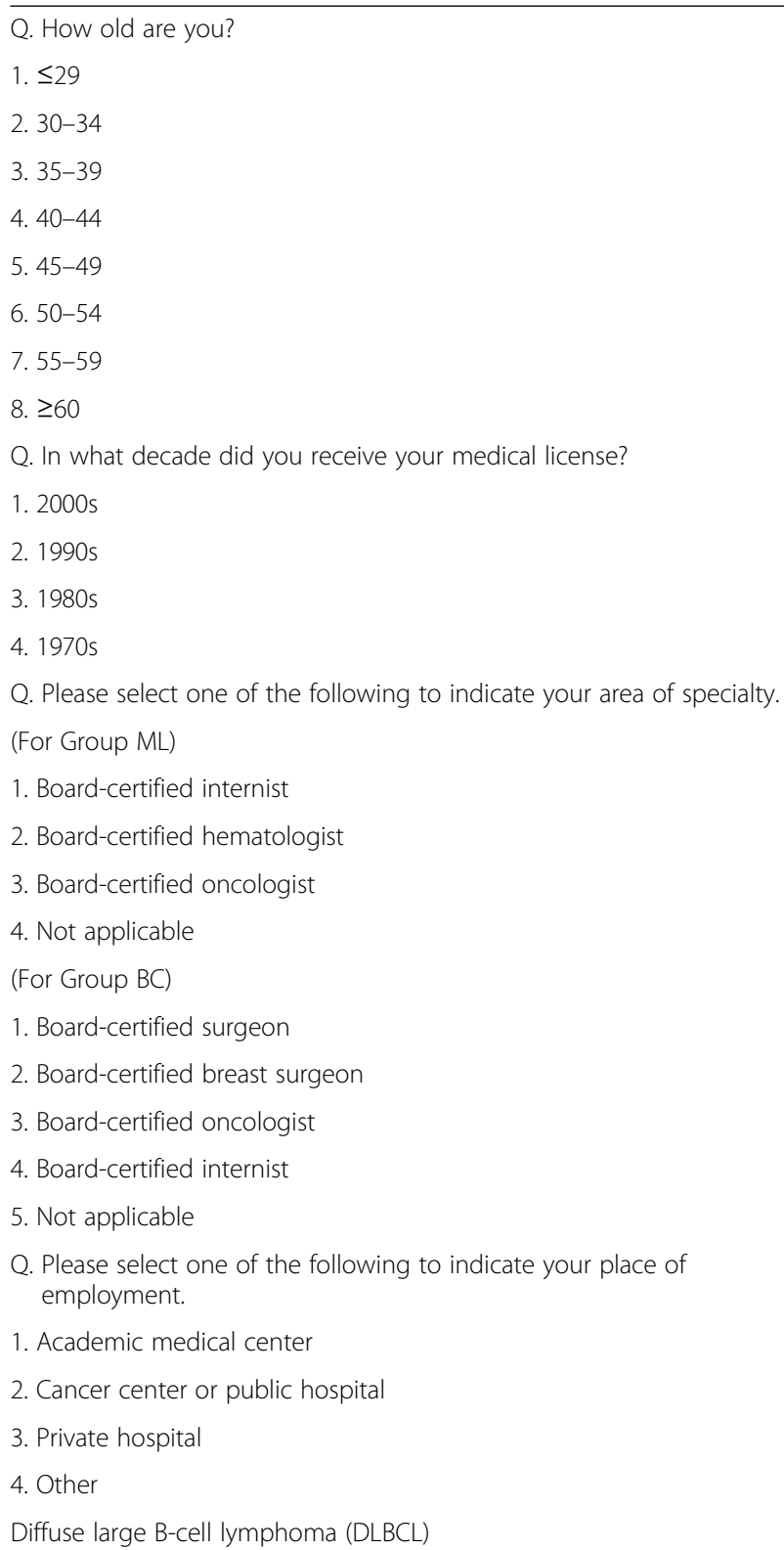

A 68-year-old woman was given a diagnosis of DLBCL, Stage IV A. There were hepatic metastases, but no bone marrow infiltration. She had no clinically significant past medical history. The International Prognostic Index was high-intermediate risk. Performance status (PS) was 0 . Lactate dehydrogenase (LDH) was $1,250 \mathrm{IU} / \mathrm{L}$. She was scheduled to receive six cycles of R-CHOP (rituximab $375 \mathrm{mg} / \mathrm{m}^{2}$ on day 1 or day 2. cyclophosphamide $750 \mathrm{mg} / \mathrm{m}^{2}$ on day 1 , doxorubicin $50 \mathrm{mg} / \mathrm{m}^{2}$ on day 1 , vincristine $1.4 \mathrm{mg} / \mathrm{m}^{2}$ on day 1 [max $2 \mathrm{mg}$ ], prednisone $100 \mathrm{mg}$ on days 1-5) given every 21 days.

Breast cancer

A 68-year-old postmenopausal woman was given a diagnosis of right breast cancer, cT2N0M0 stage II A. She had no clinically significant past medical history. PS was 0 . Right total mastectomy was performed. Pathological findings were as follows: pT $2.0 \mathrm{~cm}$, grade 3, ly-, v-, pN1 (3/20), ER(-), PgR(-), HER2(-). She was scheduled to receive four cycles of TC (docetaxel $75 \mathrm{mg} / \mathrm{m}^{2}$ on day 1, cyclophosphamide $600 \mathrm{mg} / \mathrm{m}^{2}$ on day 1) given every 21 days.
Table 1 Questions asked in the survey (Continued)

Q1. Would you manage low-risk febrile neutropenia in patients such as those describe above on an inpatient or outpatient basis?

1. Outpatient

2. Inpatient

Q2. (For those who chose outpatient management) Which of the following choices do you feel most closely describes the treatment you usually provide to this type of patient?

1. Oral antibiotics only

2. Oral antibiotics and G-CSF

3. Observation

4. Other

Q3. (For those who chose inpatient management) Which of the following choices do you feel most closely describes the treatment you usually provide to this type of patient?

1. Intravenous antibiotics

2. Intravenous antibiotics and G-CSF

3. Other

[Clinical Course]

On the tenth day of the first cycle, she presented with a fever of $39^{\circ} \mathrm{C}$. A systematic review was unrevealing. Dietary and fluid intake was sufficient.

Blood pressure, 135/80 mmHg

HEENT: She had a clear oropharynx.

Chest: No rales or wheezes were present.

Cardiac: Normal S1 and S2. There was no murmur.

Abdomen: Soft and flat. Bowel sounds were normal.

Laboratory data: WBC:1,200/mm³, ANC:400/mm ${ }^{3}, \mathrm{Hb}: 11.4 \mathrm{~g} / \mathrm{dL}$, PLT:158,000, GOT:23 IU/L, Alb:3.6 g/dL, BUN:18.8 mg/dL, Cr:0.6 mg/dL, CRP:1.8 mg/dL

Q4. How do you modify the dose of subsequent courses of chemotherapy after febrile neutropenia? Please select one of the following options.

1. Dose reduction is not required

2. Dose reduction is required if febrile neutropenia was treated by intravenous antibiotics

3. Dose reduction is required at any rate

4. Other

Q5. How do you use antibiotics for the subsequent course of chemotherapy after febrile neutropenia? Please select one of the following options.

1. Antimicrobial prophylaxis deserves consideration

2. Antibiotics should be taken into account when the next episode of febrile neutropenia occurs

3. I typically do not administer antibiotics

4. Other

Q6. How do you use G-CSF for the subsequent course of chemotherapy after febrile neutropenia? Please select one of the following options.

1. G-CSF prophylaxis deserves consideration

2. G-CSF should be taken into account when neutropenia occurs

3. G-CSF should be taken into account when the next episode of febrile neutropenia occurs 
Table 1 Questions asked in the survey (Continued)

4. I typically do not administer G-CSF
5. Other
Q7. Regarding systems for managing adverse effects of outpatient
chemotherapy, please check all appropriate responses.
1. Emergency outpatient unit is open at all hours
2. Clinical laboratory is open at all hours
3. Diagnostic imaging unit is open at all hours
4. Hospital antibiogram is available
5. Health professionals provide patient and family education
6. Chemotherapy telephone helpline is available
7. Not applicable

hospitals. In Group BC, $21 \%(n=33)$ were working at academic medical centers, $29 \%(n=46)$ at cancer centers or public hospitals, and $43 \%(n=69)$ at private hospitals.

Table 3 summarizes how the respondents manage lowrisk FN. $50 \%(n=93)$ of the physicians in Group ML chose outpatient treatment for FN as compared with $65 \%(n=104)$ in Group BC $(P=0.006)$. Among the respondents who chose outpatient treatment, a higher proportion of physicians chose both oral antibiotics and
G-CSF in Group ML than in Group BC (82\% versus $53 \%, P<0.001)$. However, intravenous antibiotics and G-CSF were preferred among physicians who chose inpatient treatment for FN.

Table 4 summarizes how the respondents modify the dose of chemotherapy in patients who have FN and their attitudes toward the use of antibiotics and G-CSF for subsequent cycles of chemotherapy. In Group ML, 77 \% $(n=143)$ of the physicians responded that "dose reduction is not required" compared with $31 \%(n=49)$ in Group BC $(P<0.001)$. In Group BC, approximately one third of the physicians responded that "dose reduction is required if FN was treated by intravenous antibiotics" and another third responded that "dose reduction is required at any rate". Thirty-six percent $(n=67)$ of Group ML and $26 \%(n=42)$ of Group BC responded that "antimicrobial prophylaxis deserves consideration" $(P=0.049)$. Approximately half of the physicians in each group responded that "antibiotics are taken into account on the next episode of FN". Twenty-five percent $(n=47)$ of Group ML and $16 \%(n=26)$ of Group BC responded that "G-CSF prophylaxis deserves consideration" $(P=0.047)$. Approximately half of the physicians in each group responded that "G-CSF is taken into account when

Table 2 Demographic characteristics of respondents

\begin{tabular}{|c|c|c|c|c|c|c|}
\hline \multirow[t]{2}{*}{ Characteristic } & \multicolumn{3}{|l|}{ Group ML $(n=185)$} & \multicolumn{3}{|l|}{ Group BC $(n=160)$} \\
\hline & & Number & $\%$ & & Number & $\%$ \\
\hline \multirow[t]{8}{*}{ Age (years) } & $\leq 29$ & 5 & 3 & $\leq 29$ & 1 & 1 \\
\hline & $30-34$ & 22 & 12 & $30-34$ & 12 & 8 \\
\hline & $35-39$ & 30 & 16 & $35-39$ & 33 & 21 \\
\hline & $40-44$ & 37 & 20 & $40-44$ & 31 & 19 \\
\hline & $45-49$ & 43 & 23 & $45-49$ & 39 & 24 \\
\hline & $50-54$ & 28 & 15 & $50-54$ & 23 & 14 \\
\hline & $55-59$ & 13 & 7 & $55-59$ & 16 & 10 \\
\hline & $\geq 60$ & 7 & 4 & $\geq 60$ & 5 & 3 \\
\hline \multirow[t]{4}{*}{ Decade of medical license } & $2000 \mathrm{~s}$ & 44 & 24 & $2000 \mathrm{~s}$ & 33 & 21 \\
\hline & 1990s & 88 & 48 & $1990 \mathrm{~s}$ & 72 & 45 \\
\hline & 1980s & 46 & 25 & $1980 \mathrm{~s}$ & 46 & 29 \\
\hline & 1970s & 7 & 4 & 1970s & 9 & 6 \\
\hline \multirow[t]{5}{*}{ Specialty } & Board-certified internist & 142 & 77 & Board-certified surgeon & 131 & 82 \\
\hline & Board-certified hematologist & 141 & 76 & Board-certified breast surgeon & 58 & 36 \\
\hline & Board-certified oncologist & 18 & 10 & Board-certified oncologist & 17 & 11 \\
\hline & Not applicable & 15 & 8 & Board-certified internist & 10 & 6 \\
\hline & & & & Not applicable & 8 & 5 \\
\hline \multirow[t]{4}{*}{ Type of clinic/hospital } & Academic medical center & 59 & 32 & Academic medical center & 33 & 21 \\
\hline & Cancer center or public hospital & 59 & 32 & Cancer center or public hospital & 46 & 29 \\
\hline & Private hospital & 67 & 36 & Private hospital & 69 & 43 \\
\hline & Other & 0 & 0 & Other & 12 & 8 \\
\hline
\end{tabular}


Table 3 Management of low-risk febrile neutropenia

\begin{tabular}{|c|c|c|c|c|c|c|}
\hline & & Group M & & Group BC & & \\
\hline & & $(n=185)$ & & $(n=160)$ & & \\
\hline & & Number & $\%$ & Number & $\%$ & $P$-value \\
\hline & atient management & & & & & \\
\hline & Outpatient & 93 & 50 & 104 & 65 & $P=0.006$ \\
\hline & Inpatient & 92 & 50 & 56 & 35 & $P=0.006$ \\
\hline & Total & 185 & 100 & 160 & 100 & \\
\hline & e outpatient management) Treatme & & & & & \\
\hline & Oral antibiotics only & 14 & 15 & 47 & 45 & $P<0.001$ \\
\hline & Oral antibiotics and G-CSF & 76 & 82 & 55 & 53 & $P<0.001$ \\
\hline & Observation & 0 & 0 & 2 & 2 & $P=0.499$ \\
\hline & Other & 3 & 3 & 0 & 0 & $P=0.103$ \\
\hline & Total & 93 & 100 & 104 & 100 & \\
\hline & atient management) Treatment of $F$ & & & & & \\
\hline & Intravenous antibiotics only & 9 & 10 & 5 & 9 & $P=1$ \\
\hline & Intravenous antibiotics and G-CSF & 83 & 90 & 51 & 91 & $P=1$ \\
\hline & Other & 0 & 0 & 0 & 0 & $P=1$ \\
\hline & Total & 92 & 100 & 56 & 100 & \\
\hline
\end{tabular}

Abbreviations: $F N$ febrile neutropenia

Table 4 Management of subsequent cycles of chemotherapy after low-risk FN

\begin{tabular}{|c|c|c|c|c|c|}
\hline & \multicolumn{2}{|c|}{ Group ML $(n=185)$} & \multicolumn{2}{|c|}{ Group BC $(n=160)$} & \multirow[b]{2}{*}{$P$-value } \\
\hline & Number & $\%$ & Number & $\%$ & \\
\hline \multicolumn{6}{|l|}{ Q. Dose of chemotherapy } \\
\hline Dose reduction is not required & 143 & 77 & 49 & 31 & $P<0.001$ \\
\hline $\begin{array}{l}\text { Dose reduction is required if febrile neutropenia } \\
\text { was treated by intravenous antibiotics }\end{array}$ & 18 & 10 & 56 & 35 & $P<0.001$ \\
\hline Dose reduction is required at any rate & 22 & 12 & 55 & 34 & $P<0.001$ \\
\hline Other & 2 & 1 & 0 & 0 & $P=0.501$ \\
\hline Total & 185 & 100 & 160 & 100 & \\
\hline \multicolumn{6}{|l|}{ Q. Antibiotics } \\
\hline Antimicrobial prophylaxis deserves consideration & 67 & 36 & 42 & 26 & $P=0.049$ \\
\hline $\begin{array}{l}\text { Antibiotics are taken into account on the next } \\
\text { episode of febrile neutropenia }\end{array}$ & 91 & 49 & 95 & 59 & $P=0.065$ \\
\hline I typically don't administer antibiotics & 27 & 15 & 23 & 14 & $P=1$ \\
\hline Other & 0 & 0 & 0 & 0 & $P=1$ \\
\hline Total & 185 & 100 & 160 & 100 & \\
\hline \multicolumn{6}{|l|}{ Q. G-CSF } \\
\hline G-CSF prophylaxis deserves consideration & 47 & 25 & 26 & 16 & $P=0.047$ \\
\hline G-CSF is taken into account when neutropenia occurs & 114 & 62 & 75 & 47 & $P=0.006$ \\
\hline $\begin{array}{l}\text { G-CSF is taken into account on the next episode of } \\
\text { febrile neutropenia }\end{array}$ & 15 & 8 & 46 & 29 & $P<0.001$ \\
\hline I typically don't administer G-CSF & 7 & 4 & 13 & 8 & $P=0.107$ \\
\hline Other & 2 & 1 & 0 & 0 & $P=0.501$ \\
\hline Total & 185 & 100 & 160 & 100 & \\
\hline
\end{tabular}


neutropenia occurs". About one third of Group BC responded that "G-CSF is taken into account when the next episode of FN occurs".

Table 5 shows the details of the systems used to manage adverse effects of outpatient chemotherapy. For this analysis, physicians who work at clinics with less than 12 beds were not included in Group ML, but were included in Group BC. Eight percent $(n=12)$ of physicians in Group $\mathrm{BC}$ worked at clinics with less than 20 beds. Eighty-six percent $(n=159)$ of Group ML and $70 \%(n=112)$ of Group BC responded that the "emergency outpatient unit is open at all hours". Sixty-nine percent $(n=128)$ of Group ML and $41 \%(n=66)$ of Group BC responded that the "clinical laboratory is open at all hours". Moreover, $63 \%$ $(n=117)$ of Group ML and $33 \%(n=52)$ of Group BC responded that the "diagnostic imaging unit is open at all hours". Only $15 \%(n=27)$ of physicians in Group ML and $16 \%(n=26)$ of those in Group BC group responded that a "chemotherapy telephone helpline is available".

\section{Discussion}

The most important finding of our study is that many Japanese physicians reduce the dose of chemotherapeutic agents after the first episode of low-risk FN in patients with potentially curable aggressive non-Hodgkin's lymphoma or early-stage breast cancer. In the questionnaire, we presented the case of a patient who had FN during treatment for aggressive non-Hodgkin's lymphoma or early-stage breast cancer in an outpatient setting (Table 1). She was clinically stable without significant medical comorbidity on presentation. Her MASCC score $[12,13]$ was 24 , and she was classified as Talcott's Group 4 [14], indicating low-risk FN. As for the subsequent course of chemotherapy, a higher proportion of physicians in Group BC responded that "dose reduction is required at any rate" or that "dose reduction is required if FN was treated by intravenous antibiotics" than in Group ML.

As mentioned in the introduction, there is wellestablished evidence supporting the clinical significance of RDI and its impact on survival in patients with aggressive non-Hodgkin's lymphoma or early stage breast cancer [1-6]. This is why reducing the dose and delaying chemotherapy should be avoided. FN and severe prolonged neutropenia can lead to the decision to reduce chemotherapy dose and delay subsequent treatment cycles. In addition, the risk of fatal infection rises as the absolute neutrophil count falls below $500 / \mathrm{mm}^{3}$ and is higher in those with a prolonged neutropenia duration ( $>7$ days) [16]. Therefore, management of afebrile and febrile neutropenia is significant. The Cochrane Haematological Malignancies Group published a review that compare the effectiveness of prophylactic administration of G-CSF or Granulocyte Macrophage ColonyStimulating Factor (GM-CSF) with antibiotics in cancer patients receiving chemotherapy [17]. Two randomized controlled trials were eligible. This review showed nonsignificant results favoring antibiotics for preventing fever or hospitalization for FN compared with G-CSF. However, in one of the two trials, the chemotherapy dose intensity received by the antibiotic comparison group was much lower than in the GM-CSF group [18], which may explain the increased incidence of infections in the GM-CSF group. A non-randomized comparison within a randomized controlled trial (GEPARTRIO study) lead to a different outcome [19]. In breast cancer patients receiving TAC (docetaxel, doxorubicin and cyclophosphamide) pegfilgrastim alone or pegfilgrastim plus antibiotics provided suboptimal protection against FN and antibiotics alone was least effective.

Our results showed that that G-CSF and antibiotics are not commonly administered as prophylaxis against FN by Japanese physicians. G-CSF use for the management of established afebrile neutropenia was preferred in both groups. Guidelines recommend against the use of G-CSF in patients with afebrile neutropenia [20-23]. A randomized, double blind, placebo-controlled trial of G-CSF has been performed in afebrile outpatients with severe chemotherapy-induced neutropenia [24]: G-CSF

Table 5 System for managing adverse effects during outpatient chemotherapy

\begin{tabular}{|c|c|c|c|c|c|}
\hline & \multicolumn{2}{|c|}{ Group ML $(n=185)$} & \multicolumn{2}{|c|}{ Group BC $(n=160)$} & \multirow[b]{2}{*}{$P$-value } \\
\hline & Number & $\%$ & Number & $\%$ & \\
\hline \multicolumn{6}{|c|}{$\begin{array}{l}\text { Q. Regarding the system for managing adverse effects of outpatient chemotherapy, } \\
\text { please check all appropriate responses }\end{array}$} \\
\hline Emergency outpatient unit is open at all hours & 159 & 86 & 112 & 70 & $P<0.001$ \\
\hline Clinical laboratory is open at all hours & 128 & 69 & 66 & 41 & $P<0.001$ \\
\hline Diagnostic imaging unit is open at all hours & 117 & 63 & 52 & 33 & $P<0.001$ \\
\hline Hospital antibiogram is available & 105 & 57 & 40 & 25 & $P<0.001$ \\
\hline Health professions provide patient and family education & 81 & 44 & 52 & 33 & $P=0.035$ \\
\hline Chemotherapy telephone helpline is available & 27 & 15 & 26 & 16 & $P=0.765$ \\
\hline Not applicable & 0 & 0 & 11 & 7 & $P<0.001$ \\
\hline
\end{tabular}


shortened the duration of neutropenia, but did not decrease the hospitalization rate for FN, length of hospital stay, the number of days of antibiotic therapy, and the likelihood of having a positive culture.

Guidelines support the use of G-CSF in patients with FN who are at high risk for infection-associated complications [20-23]. A randomized, open-label, nonplacebo-controlled trial has evaluated the effectiveness of adding G-CSF to antibiotic therapy in patients with solid tumors and chemotherapy-induced high-risk FN [25]. Adding G-CSF to antibiotic therapy was found to shorten the duration of neutropenia and reduce the duration of antibiotic therapy and hospitalization, but the treatment success rate, time to fever resolution, and mortality rate were similar in both treatment arms. Contrary to such evidence, many physicians use G-CSF with therapeutic intent.

In Japan, the majority of cancer care, including chemotherapy for solid tumors, has been historically performed by surgeons. Moreover, there is a shortage of medical oncologists in Japan. As of 2015, only 954 physicians have become Board-Certified Medical Oncologists of the Japanese Society of Medical Oncology (JSMO) [26]. Oncology education and training system in Japan needs much improvement. In addition, pegfilgrastim was not available in Japan until November 2014, and hospital visits on successive days were required. These factors may have a negative impact on outpatient management of chemotherapy and supportive care.

The Japanese Breast Cancer Society has developed Clinical Practice Guidelines for the systemic treatment of breast cancer [27]. These guidelines do not report how to use G-CSF or antibiotics as curative-intent chemotherapy. Including information about RDI and supportive measures into these guidelines may be an effective way to improve maintenance of dose-intensity.

About $50 \%$ of Group ML and $35 \%$ of Group BC chose to have the patient admitted to hospital for the treatment of FN. The American Society of Clinical Oncology (ASCO) clinical practice guidelines recommends outpatient management of low-risk FN as an option for carefully selected patients [28]. Based on the ASCO's members' expert opinion, "access to a telephone and transportation $24 \mathrm{~h}$ a day" is one of the requirements for outpatient treatment. However, our survey revealed that support systems for outpatient chemotherapy have not been adequately established in many hospitals and clinics in Japan.

Our study has several important limitations. First, the respondents may have been forgetful or may have responded without understanding the full context of the situation presented in the survey. In addition, eligible respondents were limited to physicians who had access to the website, potentially introducing self-selection bias.
Despite these limitations, we believe that our study represents an important step in the improvement of cancer chemotherapy in Japan.

\section{Conclusions}

In summary, our results suggest that supportive measures to deliver full dose-intensity chemotherapy are not widely used by Japanese physicians. Systems to support outpatient chemotherapy should thus be improved.

\begin{abstract}
Abbreviations
RDI: Relative dose intensity; ML: Malignant lymphoma; BC: Breast cancer; FN: Febrile neutropenia; DLBCL: Diffuse large B-cell lymphoma; G-CSF: Granulocyte-colony stimulating factor; DLCL: Diffuse large-cell lymphoma; ARDI: Average relative dose intensity; 5-FU: 5-fluorouracil; RFS: Relapsefree survival; OS: Overall survival; MASCC: Multinational Association for Supportive Care in Cancer; GM-CSF: Granulocyte Macrophage ColonyStimulating Factor; ASCO: American Society of Clinical Oncology.
\end{abstract}

\section{Competing interests}

The authors declare that they have no competing interests.

\section{Authors' contributions}

HS, NK and GK conceived of and designed the study. HS performed statistical analysis and drafted the manuscript. HS and NK carried out the questionnaire survey. NK helped to draft the manuscript. NK and GK participated throughout the study and critically reviewed the manuscript. All authors read and approved the final manuscript.

Authors' information

Not applicable.

\section{Availability of data and materials}

Not applicable.

\section{Acknowledgements}

We express our gratitude to all the physicians who agreed to answer our questionnaire.

Received: 15 June 2014 Accepted: 15 September 2015

Published online: 05 October 2015

\section{References}

1. Epelbaum R, Faraggi D, Ben-Arie Y, Ben-Shahar M, Haim N, Ron Y, et al. Survival of diffuse large cell lymphoma. A multivariate analysis including dose intensity variables. Cancer. 1990;66(6):1124-9.

2. Kwak LW, Halpern J, Olshen RA, Horning SJ. Prognostic significance of actual dose intensity in diffuse large-cell lymphoma: results of a tree-structured survival analysis. J Clin Oncol. 1990;8(6):963-77.

3. Bosly A, Bron D, Van Hoof A, De Bock R, Berneman Z, Ferrant A, et al. Achievement of optimal average relative dose intensity and correlation with survival in diffuse large B-cell lymphoma patients treated with CHOP. Ann Hematol. 2008;87(4):277-83.

4. Bonadonna G, Valagussa P. Dose-response effect of adjuvant chemotherapy in breast cancer. N Engl J Med. 1981;304(1):10-5.

5. Bonadonna G, Valagussa P, Moliterni A, Zambetti M, Brambilla C. Adjuvant cyclophosphamide, methotrexate, and fluorouracil in node-positive breast cancer: the results of 20 years of follow-up. N Engl J Med. 1995;332(14):901-6.

6. Budman DR, Berry DA, Cirrincione CT, Henderson IC, Wood WC, Weiss RB, et al. Dose and dose intensity as determinants of outcome in the adjuvant treatment of breast cancer. The Cancer and Leukemia Group B. J Natl Cancer Inst. 1998;90(16):1205-11.

7. Slamon D, Eiermann W, Robert N, Pienkowski T, Martin M, Press M, et al. Adjuvant trastuzumab in HER2-positive breast cancer. N Engl J Med. 2011;365(14):1273-83.

8. von Minckwitz G, Blohmer JU, Costa SD, Denkert C, Eidtmann H, Eiermann W, et al. Response-guided neoadjuvant chemotherapy for breast cancer. J Clin Oncol. 2013;31(29):3623-30. 
9. Martin M, Seguí MA, Antón A, Ruiz A, Ramos M, Adrover E, et al. Adjuvant docetaxel for high-risk, node-negative breast cancer. N Engl J Med. 2010;363(23):2200-10.

10. Lyman GH, Dale DC, Crawford J. Incidence and predictors of low doseintensity in adjuvant breast cancer chemotherapy: a nationwide study of community practices. J Clin Oncol. 2003;21(24):4524-31.

11. Lyman GH, Dale DC, Friedberg J, Crawford J, Fisher RI. Incidence and predictors of low chemotherapy dose-intensity in aggressive non-Hodgkin's lymphoma: a nationwide study. J Clin Oncol. 2004;22(21):4302-11.

12. Klastersky J, Paesmans M, Rubenstein EB, Boyer M, Elting L, Feld R, et al. The Multinational Association for Supportive Care in Cancer risk index: A multinational scoring system for identifying low-risk febrile neutropenic cancer patients. J Clin Oncol. 2000;18(16):3038-51.

13. Uys A, Rapoport BL, Anderson R. Febrile neutropenia: a prospective study to validate the Multinational Association of Supportive Care of Cancer (MASCC) risk-index score. Support Care Cancer. 2004;12(8):555-60.

14. Talcott JA, Siegel RD, Finberg R, Goldman L. Risk assessment in cancer patients with fever and neutropenia: a prospective, two-center validation of a prediction rule. J Clin Oncol. 1992;10(2):316-22.

15. Kanda Y. Investigation of the freely available easy-to-use software 'EZR' for medical statistics. Bone Marrow Transplant. 2013;48(3):452-8.

16. Bodey GP, Buckley M, Sathe YS, Freireich EJ. Quantitative relationships between circulating leukocytes and infection in patients with acute leukemia. Ann Intern Med. 1966;64(2):328-40.

17. Herbst C, Naumann F, Kruse EB, Monsef I, Bohlius J, Schulz H, Engert A. Prophylactic antibiotics or G-CSF for the prevention of infections and improvement of survival in cancer patients undergoing chemotherapy. Cochrane Database Syst Rev 2009, CD007107.

18. Sculier JP, Paesmans M, Lecomte J, Van Cutsem O, Lafitte JJ, Berghmans T, et al. A three-arm phase III randomised trial assessing, in patients with extensive-disease small-cell lung cancer, accelerated chemotherapy with support of haematological growth factor or oral antibiotics. Br J Cancer. 2001;85(10):1444-51.

19. von Minckwitz G, Kümmel S, du Bois A, Eiermann W, Eidtmann H, Gerber B, et al. Pegfilgrastim +/- ciprofloxacin for primary prophylaxis with TAC (docetaxel/doxorubicin/cyclophosphamide) chemotherapy for breast cancer. Results from the GEPARTRIO study. Ann Oncol. 2008;19(2):292-8.

20. Smith TJ, Khatcheressian J, Lyman GH, Ozer H, Armitage JO, Balducci L, et al. 2006 update of recommendations for the use of white blood cell growth factors: an evidence-based clinical practice guideline. J Clin Oncol. 2006;24(19):3187-205.

21. Aapro MS, Bohlius J, Cameron DA, Dal Lago L, Donnelly JP, Kearney N, et al. 2010 update of EORTC guidelines for the use of granulocyte-colony stimulating factor to reduce the incidence of chemotherapy-induced febrile neutropenia in adult patients with lymphoproliferative disorders and solid tumours. Eur J Cancer. 2011;47(1):8-32.

22. National Comprehensive Cancer Network (NCCN) guidelines. Myeloid Growth factors. Available at: www.nccn.org. Accessed 25 September 2015.

23. Guidelines of the Japanese Society of Medical Oncology on the management of febrile neutropenia (in Japanese). http:// www.nankodo.co.jp/g/g9784524268863/, http://www.jsmo.or.jp/

24. Hartmann LC, Tschetter LK, Habermann TM, Ebbert LP, Johnson PS, Mailliard $J A$, et al. Granulocyte colony-stimulating factor in severe chemotherapyinduced afebrile neutropenia. N Engl J Med. 1997;336(25):1776-80.

25. Garcia-Carbonero R, Mayordomo Jl, Tornamira MV, López-Brea M, Rueda A Guillem V, et al. Granulocyte colony-stimulating factor in the treatment of high-risk febrile neutropenia: a multicenter randomized trial. J Natl Cancer Inst. 2001;93(1):31-8.

26. The Japanese Society of Medical Oncology. Available at: http://www.jsmo.or.jp/ Accessed 25 September 2015.

27. Mukai H, Aihara T, Yamamoto Y, Takahashi M, Toyama T, Sagara Y, et al. The Japanese Breast Cancer Society Clinical Practice Guideline for systemic treatment of breast cancer. Breast Cancer. 2015;22(1):5-15.

28. Flowers CR, Seidenfeld J, Bow EJ, Karten C, Gleason C, Hawley DK, et al. Antimicrobial prophylaxis and outpatient management of fever and neutropenia in adults treated for malignancy: American Society of Clinical Oncology clinical practice guideline. J Clin Oncol. 2013;31 (6):794-810.

\section{Submit your next manuscript to BioMed Central and take full advantage of:}

- Convenient online submission

- Thorough peer review

- No space constraints or color figure charges

- Immediate publication on acceptance

- Inclusion in PubMed, CAS, Scopus and Google Scholar

- Research which is freely available for redistribution 